\title{
Effect of carbon nanofillers on the Performance of Electromechanical Polyaniline based Composite Actuators
}

\author{
J. C. García-Gallegos ${ }^{1,2,3^{*}}$, I. Martín-Gullón ${ }^{1}$, J.A. Conesa ${ }^{1}$, Y. I. Vega-Cantú ${ }^{2,4}$, F. J. \\ Rodríguez-Macías ${ }^{2,4}$.
}

\begin{abstract}
Different types of crystalline carbon nanomaterials were used to reinforce polyaniline (PAni) for use in electromechanical bilayer bending actuators. The objective is to analyze how the structural properties of the nanocarbons affect the in-situ produced PAni structure and subsequent final composite actuator behavior. Nanocarbons investigated were multiwalled carbon nanotubes, nitrogen-doped carbon nanotubes, helical-ribbon carbon nanofibers and graphene oxide, each one presenting different shape and structural characteristics. Films of nanocarbon-PAni composite were tested in a liquid electrolyte cell system. Experimental design was used to select type of nanocarbon filler and composite loadings that showed a good balance of electromechanical properties. Raman spectroscopy suggests good interaction between PAni and the nanocarbon fillers. Electron microscopy showed best nanofiller dispersion for graphene oxide, followed by multiwall carbon nanotubes. On the contrary, nitrogen doped nanotube composites showed dispersion problems, and thus a poor performance. Multiwall carbon nanotubes composite actuators had the best performance based on the combination of bending angle, bending velocity and maximum working cycles (measured considering nanofiller loading and applied voltage), while graphene oxide attained similar good performance.
\end{abstract}

\section{Keywords}

Artificial muscle, actuator, composite, carbon nanotubes, carbon nanofibers, graphene oxide, interfacial polymerization, polyaniline.

\footnotetext{
${ }^{1}$ Department of Chemical Engineering, University of Alicante, Ap. 99-E03080, Alicante, Spain. ${ }^{2}$ Advanced Materials Department and Laboratory for Nanoscience and Nanotechnology Research (LINAN), IPICYT, Camino a la Presa San José 2055, Col. Lomas 4a, San Luis Potosí, SLP, 78216, México. ${ }^{3}$ Área de Bioingeniería, Facultad de Ingeniería, UABC, Blvd. Benito Juárez SN, Parcela 44, 21280 Mexicali, Baja California, México.

${ }^{4}$ Departamento de Química Fundamental, Universidade Federal de Pernambuco, 50.670-901, Recife- PE, Brasil.

Corresponding autor:

J.C. García-Gallegos, área de Bioingeniería, Facultad de Ingeniería, Universidad Autónoma de Baja California, Blvd. Benito Juárez SN, Parcela 44, 21280 Mexicali, Baja California, México.

E-mail: juan.carlos.garcia.gallegos@uabc.edu.mx
} 


\section{Introduction}

Among the many applications of carbon nanostructures, its use as a filler in polymer composites is the application with higher potential. Particularly, carbon nanotubes (CNT), first identified by Iijima in 1991 [1] were rapidly recognized as reinforcements for high performance, multifunctional composites due to their exceptional properties such as excellent Young's modulus, good flexibility, and high electrical and thermal conductivity [2-4]. These properties are attained due to is singular structure, which consists on a layer of graphene roll-up in a cylinder, with either i) 1 layer, yielding single wall carbon nanotubes (SWCNT), with diameters around $2 \mathrm{~nm}$ and several microns long, or ii) several concentric cylinders, yielding multiwall carbon nanotubes (MWCNT), with diameters commonly between 5 and $50 \mathrm{~nm}$, and also several microns long. Graphene basal plane is parallel to CNT axis, and then its surface is nonpolar with high contribution of dispersive energy component, indicative of tendency of self-agglomeration. To give more polar character and give different electronic properties, different alternative synthesis methods where develop to include heteroatoms in the honeycomb lattice crystalline network, like nitrogen doped carbon nanotubes $\left(\mathrm{CN}_{\mathrm{x}}\right) . \mathrm{CN}_{\mathrm{x}}$ present a similar structure to MWCNT, although with periodic closed cups along the axis, also called bamboo CNT [5]. Despite of other high energy synthesis methods, CNTs can be produced massively by catalytic chemical vapor deposition (CVD) of hydrocarbons over a transition metal at elemental state.

Carbon nanofibers (CNF) are crystalline graphitic filaments with diameters below 100 $\mathrm{nm}$, where the orientation of graphene layers with respect the filament axis is different to CNTs [6], and then the nanofiber surface consist on edges of the graphene layers, presenting a different and more reactive character than CNTs. Among different structures of CNFs, helical-ribbon carbon nanofibers [7] are produced massively and commercialized by different companies. Its structure consist on a few layer graphene ribbon forming an helical structure along the axis, as though it were stacked cups, leaving a huge hollow core, with typical nanofiber diameters between 40 and $80 \mathrm{~nm}$.

Currently, the best choice for using graphene in polymer composites is graphene oxide (GO), since i) it can be produced at industrial scale, ii) the yield is high and allow a reasonable cost, and iii) there is high yield in single layers keeping high dimensions of 
microns. In addition, GO is much more interesting for composites than other graphene forms due to its extraordinary hydrophilicity caused by functional groups based on oxygen, have also showed similar or better characteristics than CNT as fillers in composites. Several reviews [8-12] highlight advances in the field of polymer-carbon nanostructures composites.

In this work we focus on polyaniline (PAni) composites, and their application for electromechanical actuators. PAni is unique among conducting polymers since its electronic structure and electrical properties can be reversibly controlled by chargetransfer doping and by protonation [13]. It can be processed in both the insulating emeraldine base (EB) form [14] and in the conducting emeraldine salt (ES) form [15] $\left(\sigma<10^{-10} \mathrm{~S} / \mathrm{cm}\right.$ and $\sigma>1 \mathrm{~S} / \mathrm{cm}$, respectively [16]). Recently, bulk production of PAni has been reported via interfacial polymerization, a chemical oxidative polymerization of aniline at organic-aqueous acid interphase [17-19].

The mechanical properties of PAni however are poor, requiring reinforcement with other materials, where carbon nanostructures are of interest since they can enhance conductivity in addition to the improvement of the mechanical properties. Several studies about CNT [20-27] and graphene oxide [28-30], for electrical and mechanical reinforcement for PAni exist, but there have been few reports on their effect in PAni-actuators [31-33]. Carbon nanofillers in PAni actuators can eliminate the need of conductive metallic thin layers on actuator surfaces to increment their electrical conductivity. For example, Mottaghitalab et al [31] found that $1 \%$ of SWCNT increase the electrical conductivity 20 times and also duplicate the Young modulus of composite fiber actuators. However, the maximum strain decreased from 4.6 to $2.7 \%$ due to increased stiffness. Spinks et al [32] have also reported that CNT reinforcement in PAni-actuators improves their mechanical and electrical properties although in detriment of elongation.

PAni is attractive for artificial muscles, and other actuator applications, due to its shape variation in response to an electric field in a protic electrolyte [34-39]. PAni elongates when it passes from its reduced form (leucoemeraldine salt form) to a semi-oxidized conductive form (emeraldine salt) at about $0.3 \mathrm{~V}$, and can expand more at about $0.9 \mathrm{~V}$ when PAni is totally oxidized (pernigraniline salt form). At each oxidation step, the anions are inserted into the polymer chains, producing expansion. On the other hand, 
when PAni is reduced and the anions expulsed, it results in a contraction of the polymer. Several reports show that PAni in its pernigraniline form results in mechanically unstable actuators $[16,37,40]$. As a consequence, actuation probes should only operate from leucoemeraldine to emeraldine salt form (first oxidation peak), although Smela et al [37]. report that the use of methanosulfonic acid (MSA), or other dopant similar acids, could decrease mechanical damage on actuators in pernigraniline salt form.

PAni based bending actuators are usually assembled though a PAni film adhered to a nonexpandable, flexible, inert film, regularly cellophane [34, 41, 42]. A thin gold layer is commonly desposited on one side of the film actuators in order to decrease the intrinsic resistivity along them $[35,37]$. One potential advantage of using nanocarbons in PAni is the possibility of eliminating the need for this film. The PAni actuator elongation varies from about 0.5 to $2.5 \%$ and the working cycles of devices varied from 100 to 5000 (the higher limit attained only under controlled conditions).

MWCNT-PAni composite actuators have been studied the most; in this work we compared them to actuators with nitrogen-doped carbon nanotubes $\left(\mathrm{CN}_{\mathrm{x}}\right)$, helical-ribbon carbon nanofibers (HR-CNF) and graphene oxide (GO) nanoplatelets. In $\mathrm{CN}_{\mathrm{x}}$, nitrogen replaces carbon atoms in the graphene sheets, making them more reactive than undoped MWCNTs, which could improve interactions with the PAni matrix [43-45]. HR-CNFs have a much more reactive surface due to the edges exposed along the fiber, which allows good dispersions in polymeric matrices [46-47]. The chemical exfoliation of helical ribbon-carbon nanofibers (HR-CNF) can produce single-layer GO [48], which we also used to compare which nanofiller gave the best PAni-composite actuator performance.

\section{Experimental}

\subsection{Materials}

Aniline ([ $\left.\mathrm{C}_{6} \mathrm{H}_{7} \mathrm{~N}\right]$ 97\%, Sigma-Aldrich) and toluene (ACS reagent, Sigma-Aldrich) were used as received. Ammonium persulfate, APS, [( $\left.\mathrm{NH}_{4}\right)_{2} \mathrm{~S}_{2} \mathrm{O}_{8} 97 \%$, Sigma-Aldrich] was used as polymerization oxidant. Hydrochloric acid (ACS reagent, 37\%, Sigma-Aldrich) and methane sulfonic acid (MSA, $\geq 99.5 \%$, Sigma-Aldrich) were used as PAni-dopants and electrolytes. Methanol (ACS reagent, 99.8\%, Sigma-Aldrich) was used to remove unreacted aniline and byproducts from the PAni composite. 
MWCNTs were produced in-house by CVD method described elsewhere [49]. Basically, a $2.5 \mathrm{wt} \%$ ferrocene in toluene liquid solution is vaporized and entrained with an argon flow of $2.5 \mathrm{~L} / \mathrm{min}$ to a quartz tubular reactor a constant temperature of $800^{\circ} \mathrm{C}$ for $30 \mathrm{~min}$. MWCNTs were purified by dispersing them with a pulsed probe sonicator in water, followed by reflux in $\mathrm{HCl}(6 \mathrm{M})$ and finally are filtrated to remove metal catalyst and amorphous carbon, based on the method of Alvizo-Paez et al [5]. MWCNTs present an average of 15-30 nm of diameter and tenths of microns long. $\mathrm{CN}_{\mathrm{x}}$ were produced following the same equipment and procedure for MWCNT, but using benzylamine instead of toluene, and it is fully described elsewhere [50]. $\mathrm{CN}_{\mathrm{x}}$ present similar dimensions to MWCNTs. Commercial grade HR-CNF were kindly supplied by Grupo Antolin (Burgos, Spain), who produces and commercialized these nanofibers through the trade mark GANF, and their structure and properties are fully described elsewhere [31, 41]. HR-CNF present an average of 40-60 nm diameters and 10-15 microns long, although they were nested since they were produced in a floating catalyst reactor. GO was produced in house staring from GANF following a modified Hummers and Offemann method, basically a $\mathrm{KMnO}_{4}$ treatment in concentrated $\mathrm{H}_{2} \mathrm{SO}_{4}$, following Varela-Rizo et al [48] procedure. There is high yield in monolayered graphene sheets, with lateral size of 0.2 to $1 \mu \mathrm{m}$.

\subsection{General Composite Synthesis Procedure}

PAni-composites were synthetized in-situ by interfacial polymerization, which requires the organic phase containing the monomer $(1.95 \mathrm{~mL}$ of aniline in $50 \mathrm{~mL}$ of toluene $)$ and the aqueous phase with the oxidant and an acid [15-17] (2.45 g of APS in $100 \mathrm{~mL}$ of either $1 \mathrm{M} \mathrm{HCl}$ or MSA), and a molar ratio 2:1 for aniline:APS. The carbon nanofilament materials (MWCNT, $\mathrm{CN}_{\mathrm{x}}, \mathrm{HR}-\mathrm{CNF}$ ) were dispersed in the aqueous solution, prior to the addition of the acid and the APS, with a high shear rotor- stator mixer (Silverson LR4), for $8 \mathrm{~min}$ at $7000 \mathrm{rpm}$. GO was dispersed in the aqueous phase by ultrasonication (Aname ultrasonic processor, $40 \%$ power, $3 \mathrm{~h}$ ), where $\mathrm{GO}$ is at the same time exfoliated to obtain monolayer GO. The organic and aqueous solutions were stirred magnetically in a flask for $3 \mathrm{~h}$.

Screening experiments were done with all four nanofillers, adding 10 and $30 \mathrm{mg}$ to the aqueous phase (given the polymerization yield this results in composites with 1.1 and 3.3 
wt-\% reinforcement). Additional composites were synthetized with MWCNT and GO, adding 4.7, 8, 12.4, 16, 24 and $33.9 \mathrm{mg}$ for MWCNT and GO PAni-composites for final loadings of $0.55,0.91,1.84,2.60$ and 3.94 wt-\% (based on a Central Composite Design $-\mathrm{CCD}-$ of experiments for three factors [51]).

After polymerization, the composites were collected over $0.45 \mu \mathrm{m}$ pore size membranes under vacuum filtration, and washed with $150 \mathrm{~mL}$ of methanol. Finally, the composites were dedoped with $60 \mathrm{~mL}$ of $0.2 \mathrm{M} \mathrm{NaOH}$, and further washed three times with $30 \mathrm{~mL}$ distilled water, yielding neutral eluate portions at the end.

\subsection{Preparation of Bending Actuators}

Dedoped PAni-composites were dissolved in N-methyl-pyrrolidone (NMP) at 10\% w/v ratio, then casted on a glass surface, and finally dried at $70^{\circ} \mathrm{C}$ in a vacuum furnace. Films with around $40 \mu \mathrm{m}$ of thickness were peeled off adding $1 \mathrm{M} \mathrm{HCl}$ or $1 \mathrm{M} \mathrm{MSA}$. Strips of approximately $6 \times 20 \mathrm{~mm}$ were cut. To assembly the actuator, the composite strip is adhered to adhesive cellophane tape placing a small piece of $\mathrm{Al}$ foil $(3 \times 3 \mathrm{~mm})$ and a $\mathrm{Cu}$ wire (for connecting with voltage source) between film ends (see figure 1), to ensure a good contact between the $\mathrm{Cu}$ wire, $\mathrm{Al}$ foil, and composite film.

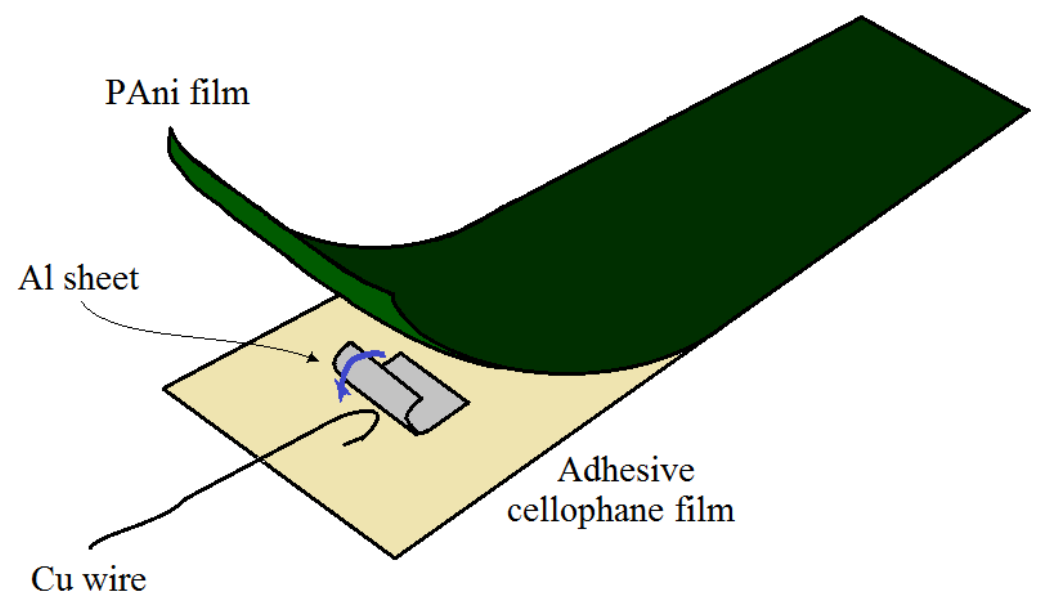

Figure 1. Preparation of PAni bilayer bending actuators. The adhesive side of cellophane film is in contact with wire $\mathrm{Cu}, \mathrm{Al}$ foil and polyaniline composite film.

Initially, film bilayer bending actuators were tested (by quadruplicate) in $1 \mathrm{M} \mathrm{HCl}$ and 1 M MSA electrolytes at $\pm 0.5, \pm 1.0, \pm 2.0, \pm 3.5$ and $\pm 5.0 \mathrm{~V}$ in a two electrode cell system as screening experiments. This system was selected since it is more adequate for these 
technological applications than a three electrode cell. Photographs of actuators (taken each 10 seconds) under testing were analyzed to obtain their flexion and response time.

A Central Composite Design (CCD) of Experiments for three factors was employed with all MWCNT and GO based composites. Bilayer actuators were tested using voltages of $0.5,0.88,1.0,1.5,2.0,2.5,3.0,3.5$ and $4.95 \mathrm{~V}$ in a two electrode cell system, evaluating extent and velocity of flexion, and working cycles, using 1 M MSA as electrolyte. Photographs of actuators (taken each 10 seconds) under testing were analyzed to obtain the response of variables under study. The ANOVA (analysis of variance) of the experiments and their response surfaces were obtained using Design Expert 7.1.5 (software specialized in statistical analysis).

\subsection{Composite Characterization}

The morphology and dispersion of nanofillers in unprocessed and processed composites, in adequate ultramicrotomes, were observed by scanning electron microscopy (SEM Hitachi S3000N) by transmission electron microscopy (JEOL TEM 2010). Raman spectroscopy using a HeNe laser $(633 \mathrm{~nm})$ was done to every nanocarbon and to all the composites with nanofiller content of 1.1 and $3.3 \mathrm{wt}-\%$. Electrical conductivity of composites-films $(10 \mathrm{~mm}$ side, about $40 \mu \mathrm{m}$ thickness, cast from 10\%w/v dedoped composite solutions in NMP and subsequently redoped ) was measured with a four point probe $(0.7 \mathrm{~mm}$ of distance between points) using a Keithley 2400 voltage source. Composite film strips (about $40 \mu \mathrm{m}$ thickness, $1.6 \times 20 \mathrm{~mm}$, in the redoped form) were tested by thermo-mechanical analysys (TMA) at $0.1 \mathrm{~N}$ (tension), $5^{\circ} \mathrm{C} / \mathrm{min}, 35-450^{\circ} \mathrm{C}$ using a TA Instruments Q400.

\section{Results and discussion}

The average polymeric yields when synthesizing neat PAni was $49 \%$ and $47.7 \%$, using $\mathrm{HCl}$ and $\mathrm{MSA}(1 \mathrm{M})$ as dopants, respectively. $\mathrm{HCl}$ was chosen for subsequent production of all the nanocarbon composites.

\subsection{Characterization of composites}

Figure 2 shows the microscope images of PAni based composites with each nanocarbon at $1.1 \mathrm{wt}-\%$. Each row of images in figure 2 contains the different explorations carried out with each nanocarbon composites, by this order, MWCNT, CNx, HR-CNF and GO. 
Left column images of figure 2 shows the SEM micrographs of as produced PAni based composites, which present a nanofibrilar structure, as expected [15-17], which is more defined for HR-CNF and GO, figure 2(i) and figure 2(m) micrograph, respectively. Next column shows the SEM images of processed composite casted films, showing differences in rugosity depending on the nanofiller, presenting HR-CNF and GO composites the smoother surface, and $\mathrm{CN}_{\mathrm{x}}$ based one the more wavy texture. Last two columns show the TEM images, to observe dispersion over one square micron areas (third column), and higher magnification to observe the interface (fourth column).

MWCNTs (figure 2(a-d)) showed good filler dispersion. Contrary to it was expected, big agglomerates are observed in processed $\mathrm{CN}_{\mathrm{x}}$-PAni composites (figure 2(e-h)), which may indicate that i) in NMP solutions the doped nanotubes segregate from the PAni matrix more than other nanofillers, or ii) the $\mathrm{CN}_{\mathrm{x}}$ dispersion in the aqueous phase, prior to the polymerization, was not stable enough. Although HR-CNF showed the worst dispersion in the as-synthesized composites (figure $2(\mathrm{k}, 1)$ ), their composite films showed the smoothest surface (figure 2(j)), probably because processed CNF had a low aspect ratio which allowed a good NMP penetration in all PAni regions. The best dispersion of nanofillers was observed in PAni-GO composites (figure 2(m-p)), the GO dispersion attained was the best, with isolated GO flakes in the PAni matrix frequently observed (figure 2(p)), and only scarce and small agglomerates of GO. 


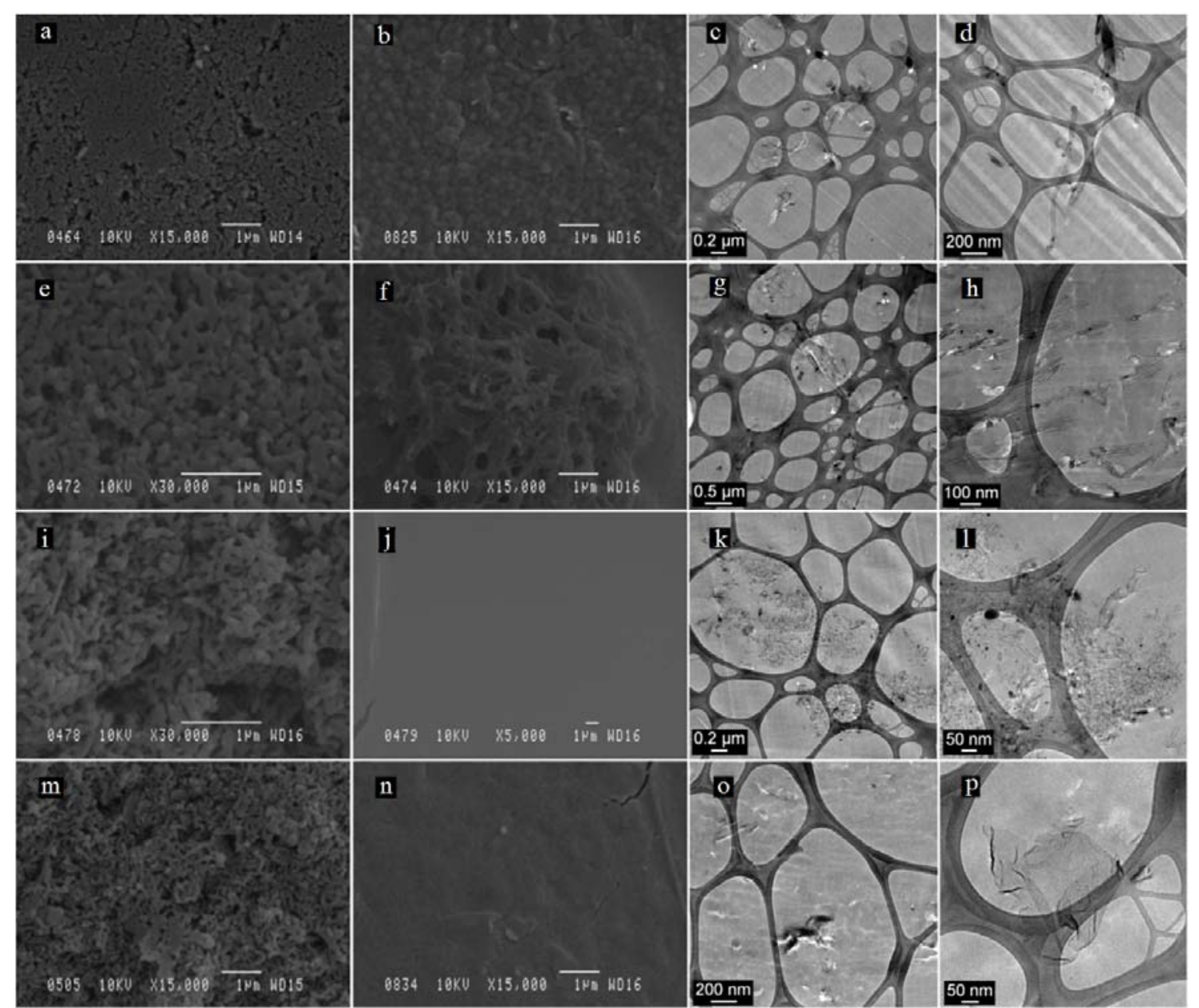

Figure 2. SEM and TEM micrographs of PAni-MWCNT (a-d), PAni-CNx (e-h), PAniHR-CNF (i-l) and PAni-GO (m-p). The first and two SEM micrographs of each composite correspond to unprocessed PAni-composite and casted NMP-PAni-composite, respectively. The restant two TEM micrographs of each row showed the filler dispersion and some filler details.

Figure 3 and figure 4 and figure 5 shows the Raman spectra of nanocarbons and nanocarbon PAni composites, respectively. Figure 3 shows typical spectra of graphitic materials, with the following identified peaks: D peak (of defect) at $\sim 1330 \mathrm{~cm}^{-1}$, G peak (of graphitic) at $\sim 1580 \mathrm{~cm}^{-1}$, and 2D (second harmonic of D band) at $\sim 2635 \mathrm{~cm}^{-1}$. The $\mathrm{I}_{\mathrm{D}} / \mathrm{I}_{\mathrm{G}}$ ratio is smallest $(0.684)$ for MWCNT indicating that, as expected, it has fewer crystalline defects, while for $\mathrm{CN}_{\mathrm{x}}$ the effect of doping increases the ratio to 1.268 , as expected, since doping is a type of defect in the $\mathrm{sp}^{2}$ carbon honeycomb array. The HRCNF shows the highest $\mathrm{ID}_{\mathrm{D}} \mathrm{I}_{\mathrm{G}}$ ratio (1.439) due to the great number of edge defects. GO shows $\mathrm{I}_{\mathrm{D}} / \mathrm{I}_{\mathrm{G}}=1.378$ suggesting that some defects active in Raman removed by the oxidation process, although the GO must present more defects through functional groups. Despite the intrinsic differences on fillers, their level of crystalinity could be summarized as follows: MWCNT $>\mathrm{CNx}>\mathrm{GO}>\mathrm{HR}-\mathrm{CNF}$. 


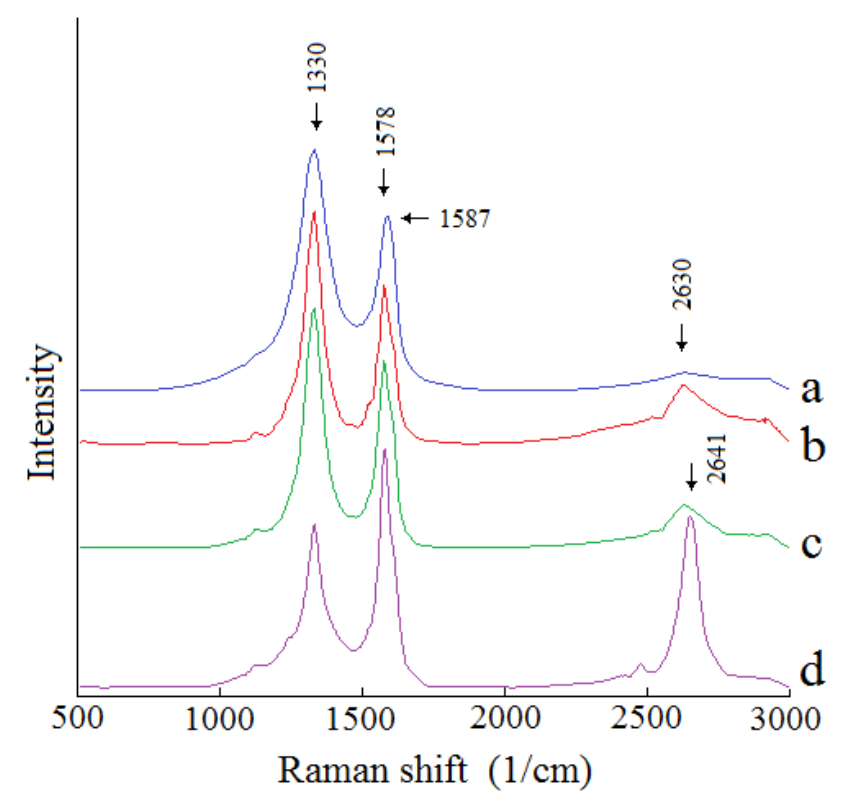

Figure 3. Raman spectrograms of fillers. (a) GO (ID/IG=1.378), (b) HR-CNF (1.439), (c) $\mathrm{CN}_{\mathrm{x}}$ (1.283), and (d) MWCNT (0.684).

Raman spectra of unprocessed-dedoped PAni-composites and processed (NMP cast and doped) composite samples (including a neat PAni), are shown in figure 4 and figure 5. Neat dedoped PAni shows a typical profile (spectra a, left panel of figure 4 and figure 5) with the quinoid ring bands at $1165\left(\mathrm{C}-\mathrm{H}\right.$ plane stretch) and $1481 \mathrm{~cm}^{-1}(\mathrm{C}=\mathrm{N}$ stretching), and the benzoid ring band at $1590 \mathrm{~cm}^{-1}$ (C-C stretching). Neat doped PAni (spectra a, right panels of figure 4 and figure 5) showed evident attenuation of those peaks, due to the irruption of the bipolaronic structure band peak $\left(\sim 1336 \mathrm{~cm}^{-1}, \mathrm{C}-\mathrm{N}^{++}\right.$stretching of bipolaron) is likely contributing to the width of this broad peak.

The D and $\mathrm{G}$ bands of carbon fillers (figure 3) overlapped with the Raman bands of doped and dedoped PAni (spectra b-e of figure 4 and figure 5). The spectra of dedoped PAniGO (spectra b-c, left panel of figure 4) and PAni-MWCNT (spectra d-e, left panel of figure 5) composites show attenuation of PAni bands. Some authors report that $\pi-\pi$ interactions between polymer chains and MWCNT can result in stronger interaction between the matrix and the carbon nanomaterial [25, 28, 29, 52], which could be also occurring with GO. For the dedoped PAni composites of HR-CNF and $\mathrm{CN}_{\mathrm{x}}$ the attenuation of the PAni peaks are smaller, suggesting differences in the interaction between this nanofillers and the polymer. However after acid doping in all Raman spectra for the composites the $\mathrm{D}$ and $\mathrm{G}$ bands of nanocarbons are more prominent than the bands 
of PAni, since there is the addition of the bipolaronic peaks of PAni plus those peaks of nanocarbons.
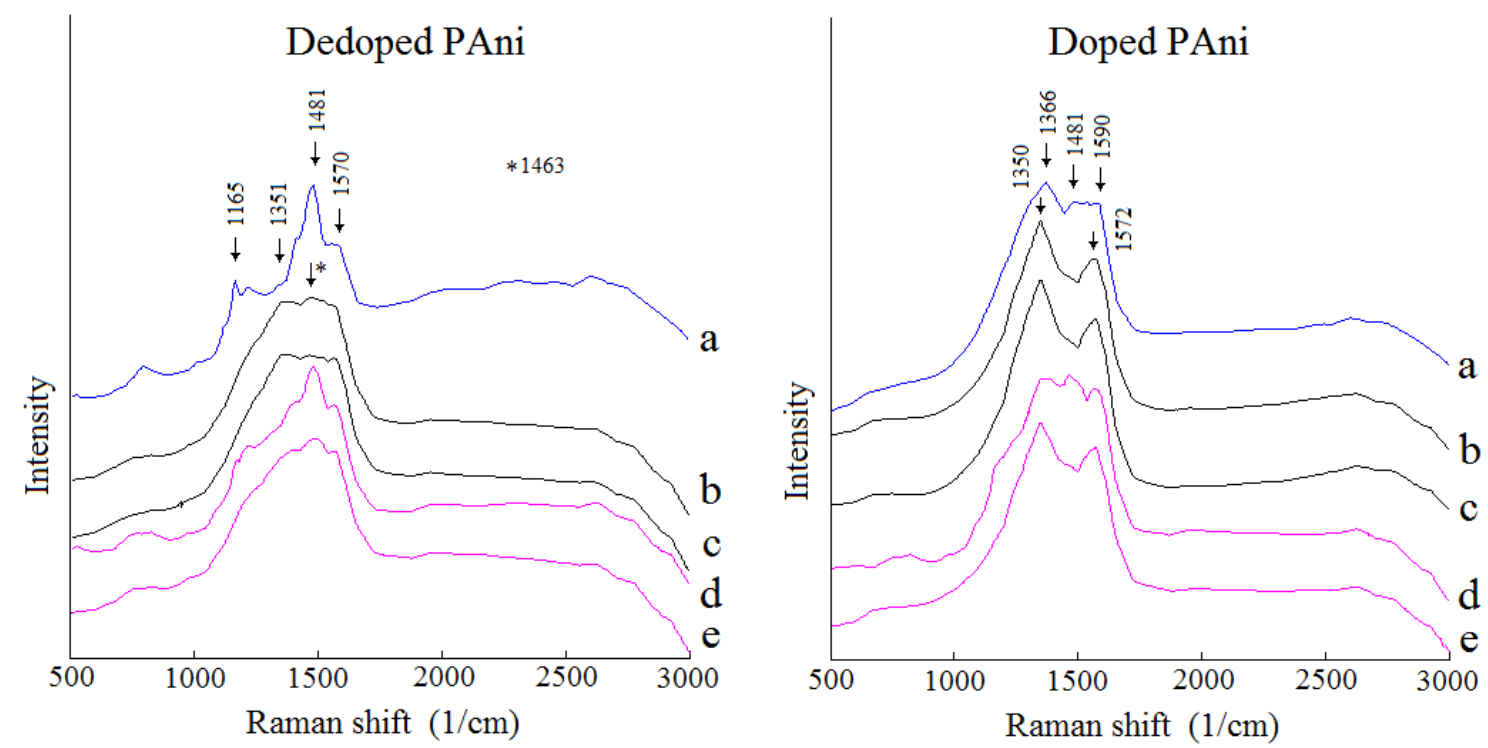

Figure 4. Raman spectrograms of dedoped (left) and doped (right) PAni-composites: (a) Neat PAni, (b) PAni-GO (3.3 wt-\%), (c) PAni-GO (1.1 wt-\%), (d) PAni-HR-CNF (3.3 wt$\%)$, (e) PAni-HR-CNF (1.1 wt-\%).
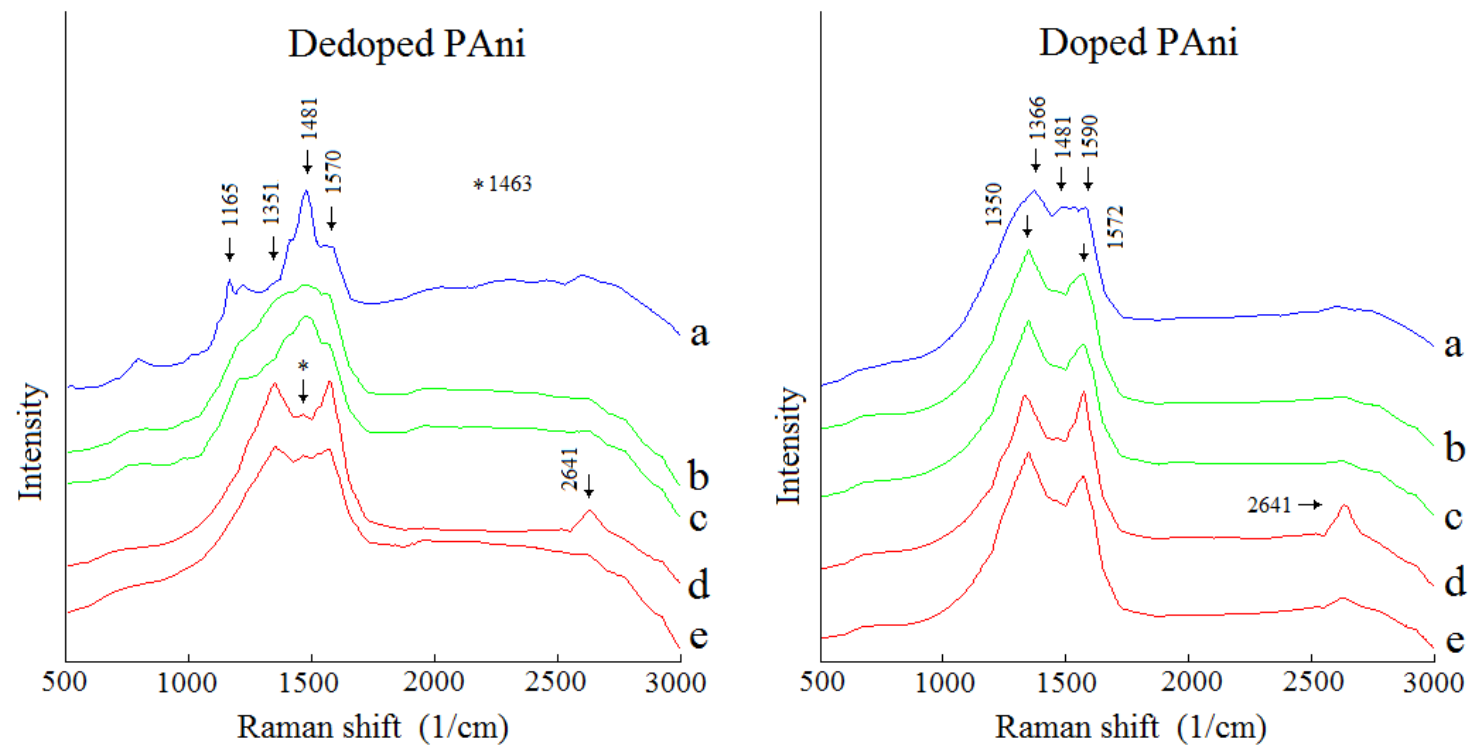

Figure 5. Raman spectrograms of dedoped (left) and doped (right) PAni-composites. (a) Neat PAni; (b) PAni-CN $\mathrm{x}_{\mathrm{x}}(3.3 \mathrm{wt} \%)$; (c) PAni-CN $\mathrm{x}$ (1.1 wt\%); (d) PAni-MWCNT (3.3 wt $\%)$; (e) PAni-MWCNT (1.1 wt $\%$ ).

Figure 6 shows the results of the thermomechanical characterization of neat PAni and the corresponding composites. The largest deformation (50-60\%) was attained in the interval 
from 140 to $230^{\circ} \mathrm{C}$ which is related to the glass transition $\left(\mathrm{T}_{\mathrm{G}}\right)$ of NMP-plastified PAni (reported to occur between $100-220^{\circ}[53,54]$ ). The highest resistance to rupture was observed for $3.3 \%$ MWCNT composites, which did not break up to $350{ }^{\circ} \mathrm{C}$, showing strains of up to $60 \%$. In general the $3.3 \%$ nanocarbon composites shows better reinforcement than the 1.1ones. In the case of $\mathrm{CN}_{\mathrm{x}}$, the reproducibility was not satisfactory, indicative of a bad dispersion problems (as shown in TEM images, figure 2(f-g)), while the reproducibility was good for HR-CNF and GO.
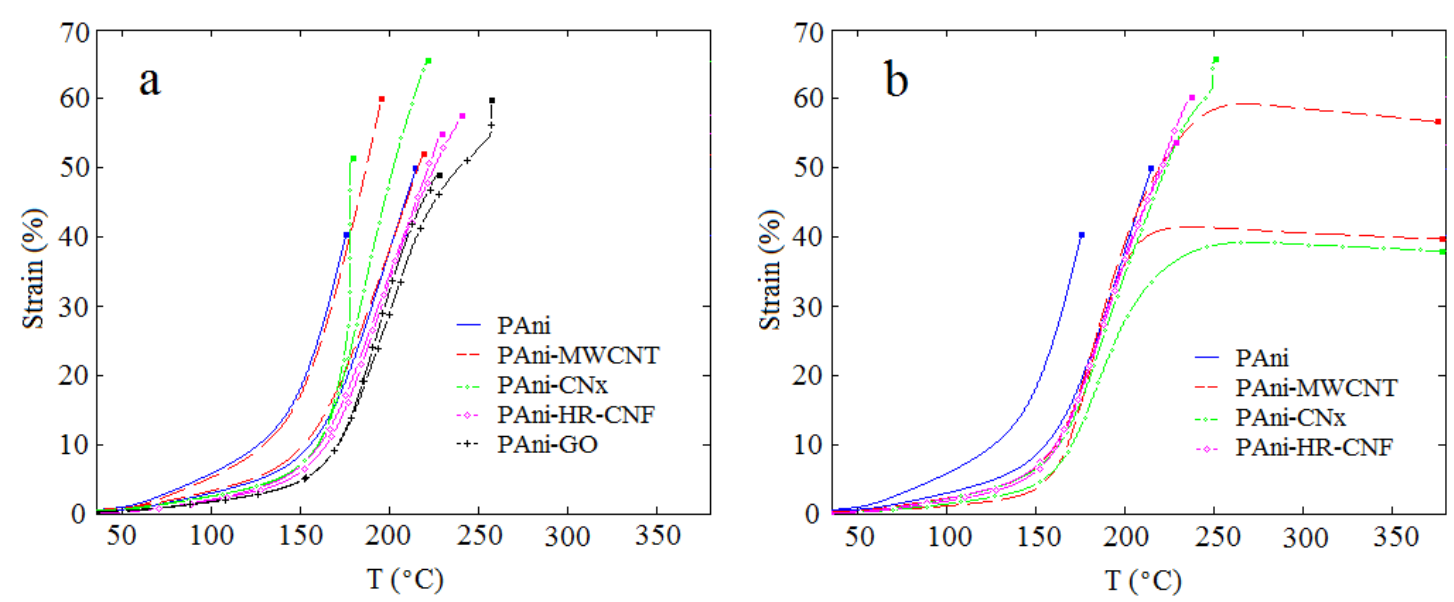

Figure 6. Thermo-mechanical analysis of PAni composite films. (a) $1.1 \mathrm{wt}-\%$; (b) 3.3 $\mathrm{wt}-\%$. The squares in profile ends indicate breaking of film trip.

The electrical conductivity of PAni composite films (shown in Table 1) was not significantly higher than that of neat PAni, except in the case of GO filler, which almost duplicated its value (from $\sim 4.8$ to $\sim 8.3 \mathrm{~S} / \mathrm{cm}$ ). Despite of their low conductivity (about $10^{-4} \mathrm{~S} / \mathrm{cm}$ ), its oxygenated chemical groups have been reported to contribute to doping PAni increasing its electrical conductivity [23] (see figure 7). Probably, a better level of dispersion of nanotubes and nanofibers could be required. In any case, the filler effect was more evident in actuation testing.

\subsection{Characterization of composite actuators}

The bending actuator screening tests showed that the largest flexion was reached with composites of $1.1 \%$ MWCNT-PAni and 3.3\% GO-PAni. In the case of MWCNT ones, their intrinsic high electrical conductivity allows bending at a lower actuation voltage (3.0 $\mathrm{V}$ while other composites had optimal actuation at $5 \mathrm{~V}$ ) and a faster response time of about 
1-1.5 min, with average flexion of $154.2^{\circ} \pm 33.4$, and up to 40 work cycles without damage. The average flexion of GO actuators was $130.8 \pm 31.7^{\circ}$, with durability of up to 28 cycles. PAni- $\mathrm{CN}_{\mathrm{x}}$ actuators showed the lowest flexion, $70^{\circ}$ using $5.0 \mathrm{~V}$, and only around 7 work cycles, even worse than unfilled PAni. HR-CNF appears to have no beneficial effects, with actuator characteristics very similar to that of PAni. Therefore, for subsequent experimentation, MWCNT and GO were selected as fillers for testing several actuation parameters with different loadings.

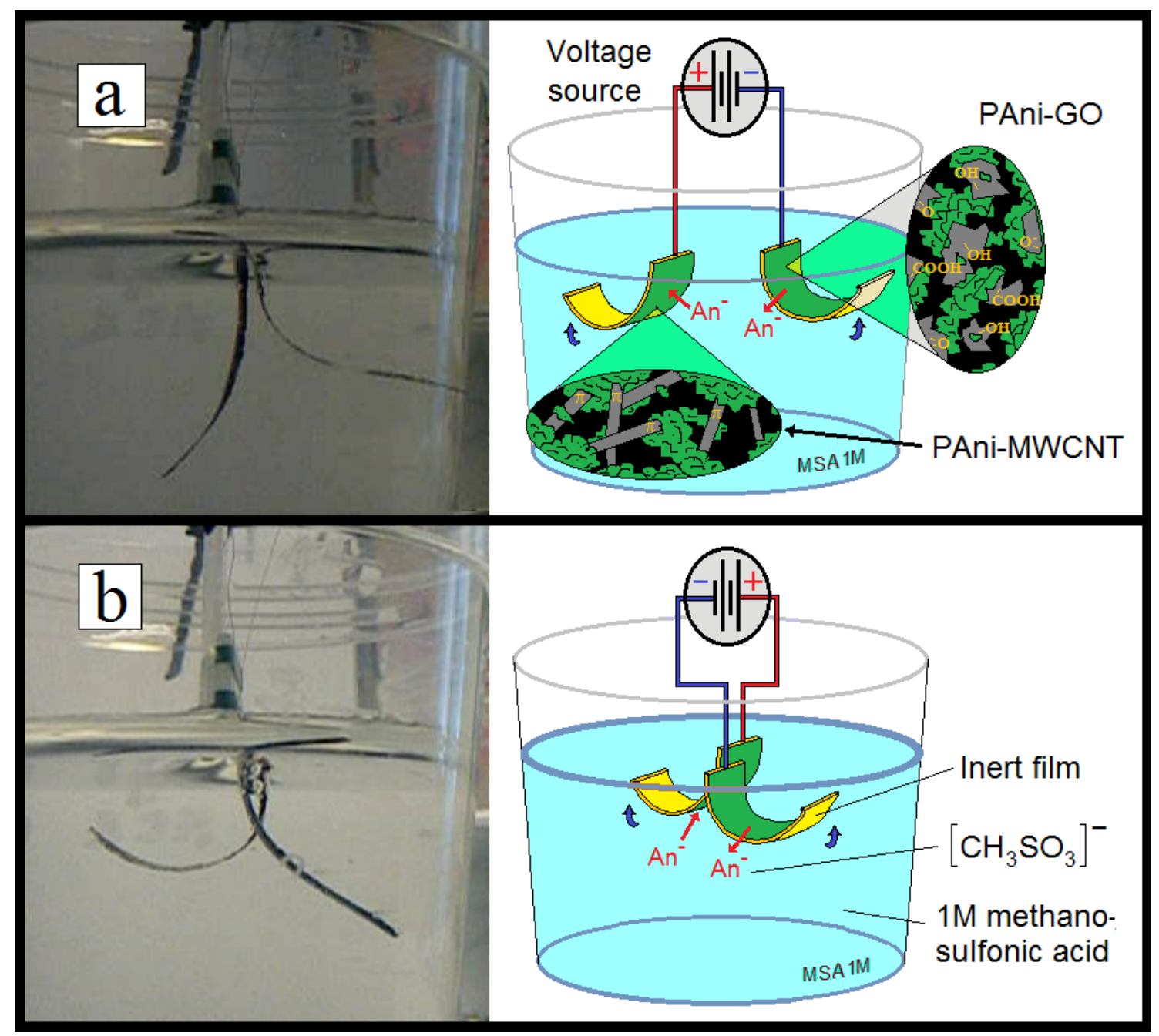

Figure 7. PAni composite actuators under testing in two electrodes cell (right, a, b). The electrolyte was $1 \mathrm{M}$ methanosulfonic acid. The inversion of voltage polarization in actuators leads to elongation/contraction (clockwise/anticlockwise movement) of them. The schemes ( $a, b$, left) represent composite actuators filled with MWCNT and GO. The positive voltage produces elongation (clockwise movement due to PAni oxidation) where solvated anions $\left(\mathrm{CH}_{3} \mathrm{SO}_{3}{ }^{-}\right)$are introduced into the reactive material to compensate the positive electrical charge in polymeric chains. The opposite occurs with negative voltage due to PAni reduction (contraction, therefore anticlockwise movement) and expulsion of anions from polymer. 
Table 1. Electrical conductivity and actuation properties of composite bilayer bending actuators

\begin{tabular}{|c|c|c|c|c|c|c|}
\hline \multirow[t]{2}{*}{ Filler } & \multirow{2}{*}{$\begin{array}{l}\text { Filler } \\
\text { content (wt } \\
\%)\end{array}$} & \multirow{2}{*}{$\sigma(\mathrm{S} / \mathrm{cm})$} & \multirow{2}{*}{$\begin{array}{l}\text { Optimal } \\
\text { Actuation } \\
\text { Voltage* }\end{array}$} & \multirow{2}{*}{$\begin{array}{l}\text { Average Flexion } \\
\left({ }^{\circ}\right)^{* *}\end{array}$} & \multicolumn{2}{|c|}{ Response TimeWork } \\
\hline & & & & & $(\min )$ & Cycles \\
\hline- & - & $4.80 \pm 0.55$ & 5 & $109.2 \pm 22.7$ & 2 & $10 \pm 3$ \\
\hline \multirow[t]{2}{*}{ MWCNTs } & 1.1 & $6.14 \pm 1.14$ & 3 & $154.2 \pm 33.4$ & 1 & $40 \pm 11$ \\
\hline & 3.3 & $3.12 \pm 0.73$ & 3 & $95 \pm 25.6$ & 1.5 & $18 \pm 7$ \\
\hline \multirow[t]{2}{*}{$\mathrm{CN}_{\mathrm{x}}$} & 1.1 & $4.52 \pm 2.57$ & 5 & $61.7 \pm 29.1$ & 2 & $7 \pm 4$ \\
\hline & 3.3 & $2.94 \pm 1.65$ & 5 & $46.7 \pm 19.5$ & 2 & $5 \pm 3$ \\
\hline \multirow[t]{2}{*}{ HR-CNF } & 1.1 & $4.23 \pm 0.52$ & 5 & $110 \pm 22.9$ & 2 & $12 \pm 4$ \\
\hline & 3.3 & $4.97 \pm 0.67$ & 5 & $73.3 \pm 21.4$ & 2 & $10 \pm 3$ \\
\hline \multirow[t]{2}{*}{$\overline{\mathrm{GO}}$} & 1.1 & $8.20 \pm 4.37$ & 3 & $47.15 \pm 15$ & 1.5 & $7 \pm 3$ \\
\hline & 3.3 & $8.52 \pm 2.90$ & 3 & $130.8 \pm 31.7$ & 1.5 & $28 \pm 11$ \\
\hline
\end{tabular}

*Voltage at which the maximum flexion occurred in less than two minutes.

**The flexion was the angle between the mobile actuator end and the vertical axis when it elongates, plus the angle when it contracts.

Bending (B), bending velocity (BV) and working cycles (WC) were measured for different loadings of MWCNT and GO, at different actuation voltages using an experiment design called "Central Composite Design". This design uses three main values for each of two variables (coded $-1,0,+1)$ and an additional extreme point (coded as $-\sqrt{ } 2,+\sqrt{ } 2$ ) for a 13 experiment run (see table 2 for the actual values used). The results are shown in figure 7 as a response surfaces for each of the three results $(B, B V, W C)$ as function of nanofiller loading and actuation voltage.

The maximum flexions were $74.6 \pm 18.0^{\circ}$ for MWCNT and $106.6 \pm 24.2^{\circ}$ for $\mathrm{GO}$ composites, in both cases for loadings of $1.84 \mathrm{wt} \%$ and actuation voltage of $2.5 \mathrm{~V}$. In general terms MWCNT composite actuators showed more durability, with a higher number of working cycles. In that regard the response surface (figure 7(c)) and the results in the table show the highest number of working cycles (WC). This can be explained considering that smaller amounts of nanofiller would result in lower stiffness, and possibly higher CNT loadings could result in agglomerates which can become points for failure. It should also be considered that higher actuation voltages tend to damage the actuators, for example by converting PAni to the more fragile pernigraniline form. 
However, bending velocity values are lower under such conditions (figures 7(a, b)). At intermediate loadings (1.84 wt.\% MWCNT) and actuation voltages $(2.5 \mathrm{~V})$ the bending angle and velocity are good while still showing good numbers of working cycles $(\sim 80)$. Clearly, better results are attained for an intermediate MWCNT content. For GO composites the response surface for work cycles (Figure 7(f)) is flatter, which indicates less sensitivity to voltage and filler loading, with the best results ( $\sim 50$ cycles) usually for intermediate values (1.84 wt.\% GO, $2.5 \mathrm{~V})$. The relative insensivity to GO loading could be a result of its good dispersion, with no agglomerates which could have induced failure at higher loadings, additionally, GO flakes should be more flexible than MWCNT resulting in better toughness composites.

Three of the GO composites (experiment runs 2, 7 and 12 in table 2) showed the fastest bending velocity ( $\sim 80 \% \mathrm{~min})$. For MWCNT composites, the maximum bending velocity was smaller than for GO composites $\left(62^{\circ} / \mathrm{min}\right.$, run PAni-MWCNT 2 and $69^{\circ} / \mathrm{min}$ in run 12). For both fillers the data and the response surfaces show that higher actuation voltages increase bending velocity, albeit with a notorious decrement in working cycles.

Some studies of PAni bending actuators $[34,35]$ show a higher number of working cycles, but in more idealized conditions, with a three electrode cell potentiostat system, a degassed electrolyte, and limiting the potential to $\sim 0.9 \mathrm{~V}$, which corresponds to the first oxidation point (from reduced leucoemeraldine salt to partially oxidized emeraldine salt, without reaching the completely oxidized pernigraniline state) thus limiting the extent of actuation. We consider that the simpler two cell electrode setup we used, without degasssing the electrolyte and using voltages reaching the second oxidation point, is a more realistic test. By systematically studying the effect of filler loading under the same test conditions for all the bilayer actuators using experimental design, we can chose the nanocarbon loading and operating voltage that should produce the best electromechanical behavior.

For practical applications the number of working cycles can be more important than the bending angle and bending velocity, balancing all three variables the mathematical model obtained from the experimental design predicts an optimal loading of $1.2 \mathrm{wt} \%$ and a voltage of $2.2 \mathrm{~V}$ for both PAni/MWCNT and PAni/GO bilayer bending actuators. 
We thus synthesized PAni composites with $1.2 \mathrm{wt} \%$ MWCNT or GO and produced bilayer actuator films to testing at 2.2 V. For PAni/MWCNT actuators. This resulted in a flexion of $67^{\circ}$, a bending velocity of $37.5^{\circ} / \mathrm{min}$ and 79 working cycles. PAni/GO actuators showed a flexion of $59^{\circ}$, a bending velocity of $45.6^{\circ} / \mathrm{min}$ and 43 working cycles. These results are consistent with the ones in table 2. Further optimization could provide and even better balance between actuation and durability.

Table 2. Central Composite Design (CCD) of Experiments and the results of bending $\left(^{\circ}\right)$, bending velocity $(\% \mathrm{~min})$ and working cycles as a function of filler load (wt \%) and voltage $(\mathrm{V})$. These variables appear showing their natural values and their respectives coded values.

\begin{tabular}{|c|c|c|c|c|c|c|c|c|}
\hline \multirow[t]{2}{*}{ Actuator } & \multirow[t]{2}{*}{ Run } & \multicolumn{2}{|l|}{ Filler charge } & \multicolumn{2}{|c|}{ Potential Difference (V) } & \multirow[t]{2}{*}{$\mathrm{B}\left({ }^{\circ}\right)^{*}$} & \multirow[t]{2}{*}{$\mathrm{BV}(\% / \min )$} & \multirow[t]{2}{*}{$\mathrm{WC}$} \\
\hline & & $\begin{array}{l}\text { Actual value } \\
\text { (wt \%) }\end{array}$ & $\begin{array}{l}\text { Coded } \\
\text { value }\end{array}$ & $\begin{array}{l}\text { Actual value } \\
\text { (V) }\end{array}$ & $\begin{array}{l}\text { Coded } \\
\text { value }\end{array}$ & & & \\
\hline \multirow[t]{13}{*}{ PAni-MWCNT } & 1 & 0.91 & -1 & 1.5 & -1 & $19.6 \pm 13.7$ & $14.3 \pm 10.6$ & 116 \\
\hline & 2 & 0.91 & -1 & 3.5 & 1 & $63.7 \pm 30.4$ & $62.4 \pm 37.5$ & 18 \\
\hline & 3 & 2.6 & 1 & 1.5 & -1 & $13.9 \pm 3.5$ & $9.4 \pm 2.4$ & 42 \\
\hline & 4 & 2.6 & 1 & 3.5 & 1 & $33.3 \pm 11.4$ & $24.4 \pm 9.5$ & 12 \\
\hline & 5 & 1.84 & 0 & 2.5 & 0 & $74.6 \pm 18.0$ & $49.0 \pm 17.1$ & 91 \\
\hline & 6 & 1.84 & 0 & 2.5 & 0 & $65.8 \pm 17.2$ & $47.6 \pm 19.0$ & 70 \\
\hline & 7 & 1.84 & 0 & 2.5 & 0 & $50.6 \pm 15.1$ & $33.8 \pm 8.6$ & 66 \\
\hline & 8 & 1.84 & 0 & 2.5 & 0 & $56.9 \pm 11.3$ & $36 \pm 13.4$ & 77 \\
\hline & 9 & 1.84 & 0 & 2.5 & 0 & $69.5 \pm 15.2$ & $44.6 \pm 13.3$ & 81 \\
\hline & 10 & 3.94 & 1.414 & 2.5 & 0 & $12.3 \pm 2.3$ & $9.3 \pm 2.3$ & 5 \\
\hline & 11 & 0.55 & -1.414 & 2.5 & 0 & $32.7 \pm 7.8$ & $23.7 \pm 7.3$ & 40 \\
\hline & 12 & 1.84 & 0 & 4.98 & 1.414 & $71.4 \pm 25.2$ & $69.1 \pm 38.7$ & 13 \\
\hline & 13 & 1.84 & 0 & 0.88 & -1.414 & $19.4 \pm 11.8$ & $15.4 \pm 11.0$ & 36 \\
\hline \multirow[t]{13}{*}{ PAni-GO } & 1 & 0.91 & -1 & 1.5 & -1 & $23.4 \pm 9.8$ & $11.8 \pm 3.9$ & 9 \\
\hline & 2 & 0.91 & -1 & 3.5 & 1 & $58.5 \pm 20.0$ & $80.1 \pm 37.2$ & 20 \\
\hline & 3 & 2.6 & 1 & 1.5 & -1 & $17.0 \pm 8.4$ & $11.5 \pm 5.9$ & 22 \\
\hline & 4 & 2.6 & 1 & 3.5 & 1 & $75.0 \pm 22.0$ & $57.8 \pm 30.5$ & 23 \\
\hline & 5 & 1.84 & 0 & 2.5 & 0 & $31.9 \pm 10.0$ & $20.4 \pm 9.2$ & 37 \\
\hline & 6 & 1.84 & 0 & 2.5 & 0 & $68.4 \pm 21.7$ & $49.1 \pm 35.0$ & 35 \\
\hline & 7 & 1.84 & 0 & 2.5 & 0 & $106.6 \pm 24.2$ & $77.6 \pm 30.2$ & 44 \\
\hline & 8 & 1.84 & 0 & 2.5 & 0 & $44.1 \pm 19.7$ & $20.3 \pm 17.3$ & 51 \\
\hline & 9 & 1.84 & 0 & 2.5 & 0 & $40.8 \pm 10.3$ & $29.1 \pm 12.3$ & 49 \\
\hline & 10 & 3.94 & 1.414 & 2.5 & 0 & $23.9 \pm 7.4$ & $18.9 \pm 11.8$ & 42 \\
\hline & 11 & 0.55 & -1.414 & 2.5 & 0 & $62.1 \pm 19.7$ & $23.5 \pm 8.0$ & 40 \\
\hline & 12 & 1.84 & 0 & 4.98 & 1.414 & $57.1 \pm 18.3$ & $79.7 \pm 33.2$ & 20 \\
\hline & 13 & 1.84 & 0 & 0.88 & -1.414 & $15.4 \pm 10.2$ & $11.2 \pm 7.4$ & 14 \\
\hline
\end{tabular}

* The flexion was the angle of the mobile actuator end and the vertical axis when it elongates, plus the angle when it contracts. 


\section{PAni/MWCNT}

(a)

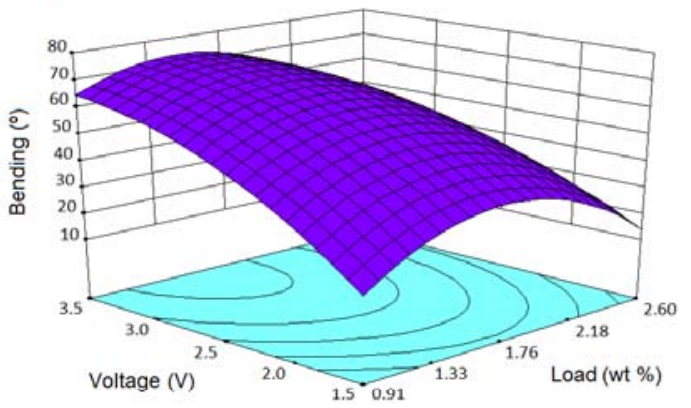

(b)

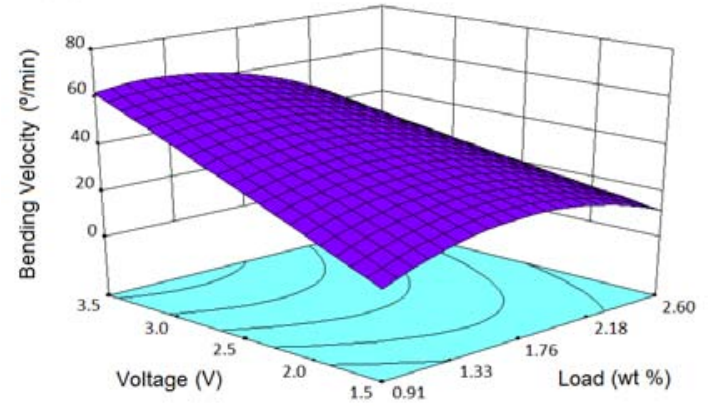

(c)

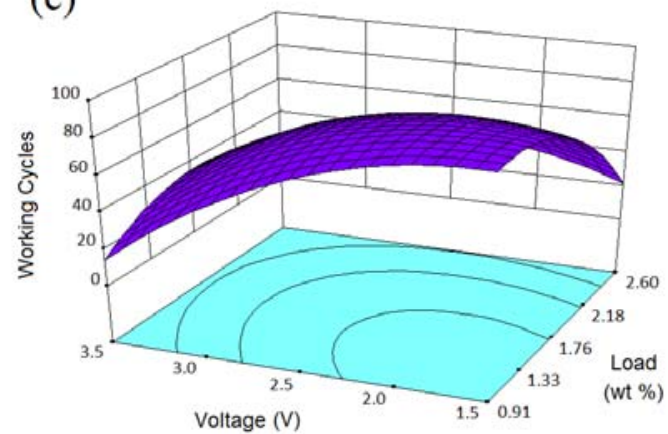

PAni/GO

(d)

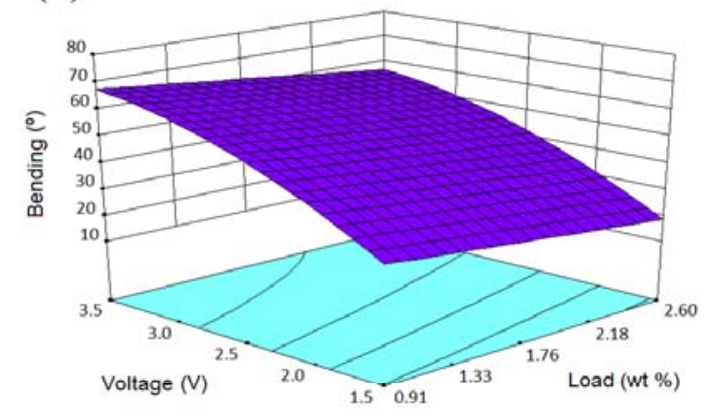

(e)

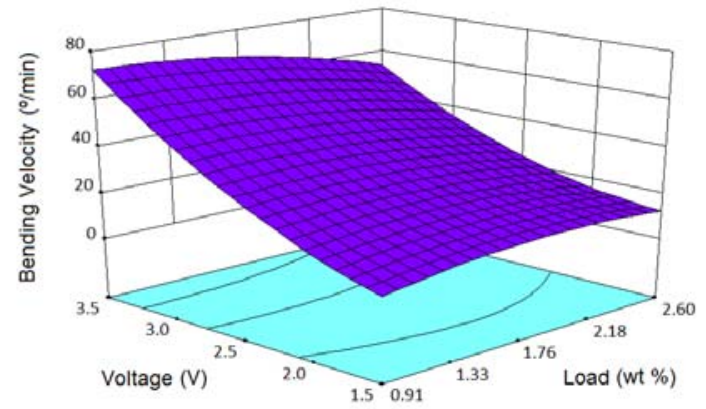

(f)

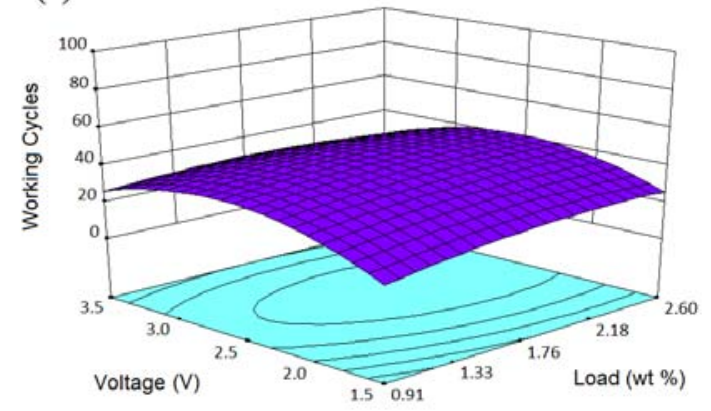

Figure 8. PAni/MWCNT and PAni/GO response surfaces of bending (a, d), bending velocity $(\mathrm{b}, \mathrm{e})$ and working cycles $(\mathrm{c}, \mathrm{f})$ as a function of voltage $(1.5-3.5 \mathrm{~V})$ and load $(0.91-2.60 \mathrm{wt} \%)$ obtained from experimental design regression quadratic models.

\section{Conclusions}

Of the four types of nanocarbons (MWCNT, $\mathrm{CN}_{\mathrm{x}}, \mathrm{HR}-\mathrm{CNF}$ and $\mathrm{GO}$ ) as fillers in PAni composites, GO and MWCNT gave better results regarding both dispersion and electrical conductivity. These fillers also worked better in actuation probes of bending strips while HR-CNF did not enhance any effect, and $\mathrm{CN}_{\mathrm{x}}$ even decremented performance. Further optimization by experimental design showed that MWCNT-PAni actuators were overall better than GO composites in bending angle, bending velocity and working cycles. These results let us know how different types of carbon nanostructures can interact (under the 
same experimental conditions) with PAni in actuation applications. Future work could extend to actuators based in other types of electroactive polymers.

\section{Acknowledgments}

JCGG thanks for scholarship support to CONACYT (2008-2010) and University of Alicante (2010-2012). YIVC and FJRM thank CONACYT for grants SEP-CB-106942 and SEP-CB-2008-107082 respectively, and the Rede NANOBIOTEC-Brasil (Edital 04/CII-2008 CAPES/MEC) for support for a visiting professor stay at UFPE.

IMG and JAC acknowledge support from University of Alicante. We also thank Ion Such Basañez and Sara Llopis Verdu for help in TMA characterization, and Cristina Almansa Carrascosa for help in electronic microscopy.

\section{References}

[1] Iijima S. Helical microtubules of graphitic carbon Nature 1991354 56-8

[2] Ajayan P M, Stephan O, Colliex C, Trauth D 1994 Aligned Carbon Nanotube Arrays Formed by Cutting a Polymer Resin - Nanotube Composite Science 265 1212-4

[3] Schadler L S, Giannaric S C, Ajayan P M 1998 Load transfer in carbon nanotube epoxy composites Appl. Phys. Lett. 73 3842-4

[4] Gojny F H, Wichmann M G H, Fiedler B, Kinloch I A, Bauhofer W, Windle AH, et al 2006 Evaluation and identification of electrical and thermal conduction mechanisms in carbon nanotube/epoxy composites Polymer 47 2036-45

[5] Alvizo-Paez E R, Romo-Herrera J M, Terrones H, Terrones M, Ruiz-García J, Hernández-López J L 2008 Soft purification of N-doped and undoped multi-wall carbon nanotubes Nanotechnology 19155701

[6] Martin-Gullon I, Vera J, Conesa J A, González J L, Merino C 2006 Differences between carbon nanofibers produced using $\mathrm{Fe}$ and $\mathrm{Ni}$ catalysts in a floating catalyst reactor Carbon 44 1572-80

[7] Vera-Agullo J, Varela-Rizo H, Conesa J A, Almansa C, Merino C, Martin-Gullon I 2007 Evidence for growth mechanism and helix-spiral con structure of stacked-cup carbon nanofibers Carbon 45 2751-8 
[8] Tasis D, Spitalsky Z, Papagelis K, Galiotis C 2010 Carbon nanotube-polymer composites: Chemistry, processing, mechanical and electrical properties Prog Polym Sci 35 357-401

[9] Ma P-C, Siddiqui N A, Marom G, Kim J-K 2010 Dispersion and functionalization of carbon nanotubes for polymer-based nanocomposites: A review Composites Part A $\mathbf{4 1}$ $1345-67$

[10] Rahmat M, Hubert P 2011 Carbon nanotube-polymer interactions in nanocomposites: A review Comp. Sci. and Tech. 72 72-84

[11] Roy N, Sengupta R, Bhowmick A K 2012 Modifications of carbon for polymer composites and nanocomposites Prog. Polym. Sci. 37 781-819

[12] Kingston C, et al. 2014 Release characteristics of selected carbon nanotube polymer composites Carbon 68 33-57

[13] Salaneck W R, Lundstrom I, Huang W-S, MacDiarmid A G 1986 A two dimensional-surface 'state diagram' for polyaniline Synth. Met. 13 291-7

[14] MacDiarmid A G, Epstein A J; Salaneck W R, Clark D T, Samuelson E J, editors 1991 Science and Applications of Conducting Polymers. Adam Hilger, Bristol, England $117-27$

[15] Angelopoulos M, Asturias G E, Ermer S P, Ray A, Scherr E M, MacDiarmid A G, Akhtar M, Kiss Z, Epstein A J 1988 Polyaniline: Solutions, Films and Oxidation State Molec. Cryst. Liq. Cryst. 160 151-63

[16] Huang W S, Humprey B D, Mac Diarmid A G 1986 Polyaniline, a novel conducting polymer. Morphology and chemistry of its oxidation and reduction in aqueous electrolytes J. Chem. Soc., Faraday Trans 1: Phys. Chem. Cond. Phases 82 2385-400

[17] Huang J, Kaner R B 2004 A general chemical route to polyaniline nanofibers JACS $126851-5$

[18] Singh P, Singh R A 2012 Preparation and characterization of polyaniline nanostructures via an interfacial polymerization method. Synth. Met. 162 2193-200

[19] Li R, Chen Z, Li J, Zhang C, Guo Q 2013 Effective synthesis to control the growth of polyaniline nanofibers by interfacial polymerization Synth. Met. 171 39-44

[20] Cochet M, Maser W K, Benito A M, Callejas M A, Martinez M T, Benoit J-M, Schreiber J, Chauvet O Synthesis of a new polyaniline/nanotube composite: "in-situ" polymerization and charge transfer through site-selective interaction. Chem. Commun. 16 $1450-1$ 
[21] Mottaghitalab V, Spinks G M, Wallace G G 2005 The influence of carbon nanotubes on mechanical and electrical properties of polyaniline fibers Synth. Met. 152 77-80

[22] Zelikman E, Narkis M, Siegmann A, Valentini L, Kenny J M 2008 Polyaniline/multiwalled carbon nanotube systems: Dispersion of CNT and CNT/PANI interaction. Polym. Eng. Sci. 48 1872-7

[23] Srivastava S, Sharma S S, Agrawal S, Kumar S, Singh M, Vijay Y K 2010 Study of chemiresistor type CNT doped polyaniline gas sensor Synth. Met. 160 529-34

[24] Blighe F M, Diamond D, Coleman J N, Lahiff E 2012 Increased response/recovery lifetimes and reinforcement of polyaniline nanofiber films using carbon nanotubes Carbon 50 1447-54

[25] Salvatierra R V, Moura L G, Oliveira M M, Pimenta M A, Zarbin A J G 2012 Resonant Raman spectroscopy and spectroelectrochemistry characterization of carbon nanotubes/polyaniline thin film obtained through interfacial polymerization. J. Raman Spectrosc. 43 1094-100

[26] Fan H, Zhao N, Wang H, Li X, Xu J 2013 Preparation of carpenterworm-like polyaniline/carbon nanotubes nanocomposites with enhanced electrochemical property Mat. Lett. 92 157-60

[27] Oueiny C, Berlioz S, Perrin F X 2014 Carbon nanotube-polyaniline composites. Prog. Polym. Sci. 39 707-48

[28] Wang H, Hao Q, Yang X, Lu L, Wang X 2009 Graphene oxide doped polyaniline for supercapacitors Electrochem. Comm. 11 1158-61

[29] Wu Q, Xu Y, Yao Z, Liu A, Shi G 2010 Supercapacitors based on flexible graphene/polyaniline nanofiber composite films ACS Nano 4 1963-70

[30] Goswami S, Maiti U N, Maiti S, Nandy S, Mitra M K, Chattopadhyay K K 2011 Preparation of graphene-polyaniline composites by simple chemical procedure and its improved field emission properties Carbon 49 2245-52

[31] Mottaghitalab V, Xi B, Spinks G M, Wallace G G 2006 Polyaniline fibres containing single-walled carbon nanotubes: enhanced performance artificial muscles Synth. Met. 156 796-803

[32] Spinks G M, Shin S R, Wallace G G, Whitten P G, Kim I Y, Kim S I, Kim S J 2007 A novel "dual mode" actuation in chitosan/polyaniline/carbon nanotube fibers Sens. Actuators B $121616-21$ 
[33] Blighe F M, Diamond D, Coleman J N, Lahiff E 2012 Increased response/recovery lifetime and reinforcement of polyaniline nanofiber films using carbon nanotubes Carbon 50 1447-54

[34] Otero T F, Martínez J G, Arias-Pardilla J 2012 Biomimetic electrochemistry from conducting polymers. A review Artificial muscles, smart membranes, smart drug delivery and computer/neuron interfaces Electrochimia Acta 84 112-28

[35] Lu W, Smela E, Adams P, Zuccarello G, Mattes B R 2004 Development of solid-inhollow electrochemical linear actuators using highly conductive polyaniline Chem. Mat. $161615-21$

[36] Smela E, Lu W, Mattes B R 2005 Polyaniline actuators Part 1. PANI (AMPS) in hcl. Synth. Met. $15125-42$

[37] Smela E, Mattes B R 2005 Polyaniline actuators: Part 2. PANI (AMPS) in methanosulfonic acid Synth. Met. 151 43-8

[38] Gu B K, Ismail Y A, Spinks G M, Kim S I, So I, Kim S J 2009 A linear actuation of polymeric nanofibrous bundle for artificial muscles Chem. Mat. 21 511-5

[39] Tominaga K, Hashimoto H, Takashima W, Kaneto K 2011 Training and shape retention in conducting polymer artificial muscles Smart Mater. Struct. 20124005

[40] Kobayashi T, Yoneyama H, Tamura H 1984 Oxidative degradation pathway of polyaniline film electrodes J. Electroanal. Chem. 177 293-7

[41] Herod T E, Schlenoff J B 1993 Doping-Induced Strain in Polyaniline: Stretchoelectrochemistry Chem. Mat. 5 951-5

[42] Kaneto K, Kaneko M, Min Y, MacDiarmid A G 1995 “Artificial Muscle": Electromechanical actuators using polyaniline films Synth. Met. 71 2211-12

[43] Ewels C P, Glerup M 2005 Nitrogen doped in carbon nanotubes J. Nanosci. Nanotechnol. 5 1345-63

[44] Fragneaud B, Masenelli-Varlot K, Gonzalez-Montiel A, Terrones M, Cavaillé J Y 2006 Efficient coating of N-doped carbon nanotubes with polystyrene using atomic transfer radical polymerization Chem. Phys. Lett. 419 567-73

[45] Ayala P, Arenal R, Rümmeli M, Rubio A, Pichler T 2010 The doping of carbon nanotubes with nitrogen and their potential applications Carbon 48 575-86

[46] Palmeri M J, Putz K W, Brinson L C 2010 Sacrifical bonds in stacked-cup carbon nanofibers: biomimetic toughening mechanisms for composite systems ACS. Nano 4 4256-64 
[47] Bortz D R, Merino C, Martin-Gullon I 2011 Carbon nanofibers enhance the fracture toughness and fatigue performance of a structural epoxy system Comp. Sci. Technol. 71 $31-8$

[48] Varela-Rizo H, Rodríguez-Pastor I, Merino C, Terrones M, Martin-Gullon I 2011 Graphene oxide nanoplatelets of different crystallinity synthesized from helical-ribbon carbon nanofibers and multiwall carbon nanotubes J. Mater. Res. 26 2632-41

[49] Kamalakaran R, Terrones M, Seeger T, Kohler-Redlich P, Rühle M, Kim Y 2000 Synthesis of Thick and Crystalline Nanotube Arrays by Spray Pyrolysis Appl. Phys. Lett. $773385-7$

[50] Terrones M, Kamalakaran R, Seeger T, Rühle M 2000 Novel nanoscale gas containers: encapsulation of $\mathrm{N}_{2}$ in CNx nanotubes Chem. Commun. 2000 2335-6

[51] Montgomery D C 2012 Design and Analysis of Experiments $8^{\text {th }}$ edition New York John Wiley \& Sons 427-72

[52] Baibarac M, Baltog I, Lefrant S, Mevellec J Y, Chauvet O 2003 Polyaniline and carbon nanotubes based composites containing whole units and fragments of nanotubes. Chem. Mater. 15 4149-56

[53] Wei Y, Jang G W, Hsueh K F, Scherr E M, MacDiarmid A G, Epstein A J 1992 Thermal transitions and mechanical properties of films of chemically prepared polyaniline Polymer 33 314-22

[54] Milton A J, Monkman A P 1993 A comparative study of polyaniline films using thermal analyses and IR spectroscopy J. Phys. D: Appl. Phys. 26 1468-74 